\title{
Desafios do cuidado de enfermagem frente à morte: reflexões sobre espiritualidade
}

\author{
Nursing care challenges in the face of death: reflections on spirituality
}

\section{Retos del cuidado de enfermería ante la muerte: reflexiones sobre espiritualidad}

\section{Recebido: 11/09/2019 \\ Aprovado: 17/05/2020 \\ Publicado: 03/03/2021}

\author{
Raquel Lima Dornfeld1 \\ Jurema Ribeiro Luiz Gonçalves ${ }^{2}$
}

Este é um estudo qualitativo realizado em 2016 em uma cidade do interior mineiro, com o objetivo de descrever as dimensões do cuidar frente à morte e a influência da espiritualidade na percepção de profissionais de enfermagem atuantes em setores de pronto-atendimento e internação de um hospital universitário. Participaram 160 indivíduos, dos quais 141 eram do sexo feminino, com idades entre 30 a 39 anos (44,3\%) e 40 a 49 anos $(21,8 \%)$. Quanto à categoria de atuação, foram 131 profissionais de nível médio (auxiliares/técnicos de enfermagem) e 29 de nível superior (enfermeiros/as), com tempo de atuação 5 a 4 anos (34,4\%) e de 10 a 14 anos (25\%), religião católica $(35,5 \%)$, seguida de espirita (32,5\%). 0 material resultante das entrevistas foi exposto à análise do Discurso do Sujeito Coletivo, com o auxílio do software DSCsoft $\mathrm{t}^{\circledR}$. 0 agrupamento das expressões-chave e ideias centrais semelhantes resultou em três categorias: Atuação profissional frente a processos de morte; Olhar para si; e Espiritualidade: dimensões e influência no contexto profissional. Os discursos revelam a espiritualidade como fonte de amparo e restauração, conquanto o sentido imanente seja reportado pelas relações entre as pessoas e o meio em que vivem. Destaca-se a importância do autocuidado e a necessidade de que os profissionais tenham espaços de acolhimento com oportunidade de ressignificação do cuidado integral frente à finitude.

Descritores: Recursos humanos; Humanização da assistência; Cuidados de enfermagem; Atitude frente à morte; Espiritualidade.

This is a qualitative study carried out in 2016, in a city in the state of Minas Gerais. It aimed to describe the dimensions of care in the face of death and the influence of spirituality on the perception of nursing professionals who work in sectors of emergency care and admission of a hospital. university. There were 160 participants, of which 141 were female, aged between 30 and 39 years old (44.3\%) and 40 to 49 years old (21.8\%). As for the category of activity, there were 131 professionals with secondary education (nursing assistants/technicians) and 29 with higher education (nurses), with experience of 5 to 4 years (34.4\%) and 10 to 14 years (25\%), The majority were Catholics (35.5\%), followed by Spiritists (32.5\%). The material resulting from the interviews was exposed to the analysis of the Collective Subject Discourse, with the aid of the DSCsoft $₫$ software. The grouping of key expressions and similar central ideas resulted in three categories: Professional performance in the face of processes of death; Self reflection; and Spirituality: dimensions and influence in the professional context. The speeches reveal spirituality as a source of support and restoration, although the immanent meaning is reported by the relationships between people and the environment in which they live. An emphasis is put on the importance of self-care and the need for professionals to have welcoming spaces with the opportunity to redefine comprehensive care in face of finitude.

Descriptors: Workforce; Humanizacion of assistance; Nursing care; Attitude to death; Spirituality.

Este es un estudio cualitativo realizado en 2016, en una ciudad del interior de Minas Gerais, con el objetivo de describir las dimensiones del cuidado ante la muerte y la influencia de la espiritualidad en la percepción de los profesionales de enfermería que trabajan en los sectores de emergencia y de hospitalización de un hospital universitario. Participaron 160 personas, de las cuales 141 eran mujeres, con edades comprendidas entre 30 y 39 años $(44,3 \%)$ y entre 40 y 49 años $(21,8 \%)$. En cuanto a la categoría de trabajo, hubo 131 profesionales de nivel medio (auxiliares/técnicos de enfermería) y 29 de nivel superior (enfermeros/as), con 5 a 4 años de trabajo $(34,4 \%)$ y 10 a 14 años (25\%), de religión católica (35,5\%), seguida de espiritista (32,5\%). El material resultante de las entrevistas se expuso al análisis del Discurso del Sujeto Colectivo, con la ayuda del software DSCsoft ${ }^{\circledR}$. La agrupación de expresiones clave e ideas centrales similares dio lugar a tres categorías: Actuación profesional ante los procesos de muerte; Mirar a ti mismo; y, Espiritualidad: dimensiones e influencia en el contexto profesional. Los discursos revelan la espiritualidad como fuente de apoyo y restauración, aunque el significado inmanente lo reportan las relaciones entre las personas y el entorno en el que viven. Se destaca la importancia del autocuidado y la necesidad de que los profesionales tengan espacios de acogida como una oportunidad para resignificar el cuidado integral frente a la finitud.

Descriptores: Recursos humanos; Humanización de la atención; Atención de enfermería; Actitud frente a la muerte; Espiritualidad.

1. Enfermeira. Especialista em Administração Hospitalar. Mestre em Atenção à Saúde. Enfermeira do Hospital de Clínicas da Universidade Federal do Triângulo Mineiro (UFTM) Uberaba, MG, Brasil. ORCID: 0000-0002-2771-7402 E-mail: rldornfeld@gmail.com

2. Enfermeira. Especialista em Terapia Comunitária. Mestre e Doutora em Enfermagem. Docente do Programa de Pós Graduação em Atenção à Saúde e do Departamento de Enfermagem em Educação e Saúde Comunitária da UFTM, Uberaba, MG, Brasil. ORCID:0000-0002-6971-5296 E-mail: juremaluiz@hotmail.com.br 


\section{INTRODUÇÃO}

A origem histórica da enfermagem remonta a práticas religiosas cujo propósito era Apromover alívio e bem-estar físico aos doentes, além de conforto espiritual, mesmo quando não havia possibilidade de cura. É possível inferir que tais preceitos permearam a construção dos ideais da enfermagem e estão presentes no senso comum acerca do exercício desta profissão ${ }^{1}$.

Ideias emergentes do meio sociocultural definem a morte como inimigo a ser vencido em prol da vida, através da busca por novos saberes, tecnologias, exames e procedimentos. A equipe de saúde assume para si o dever de lutar contra a finitude, como se fosse possível adiar ou suprimir esse componente da natureza biológica. Pode-se identificar a difusão destas ideias entre profissionais de enfermagem, bem como a crença de que devem aprimorar constantemente seu conhecimento técnico-científico para ajudar a curar os doentes sob seus cuidados ${ }^{2}$.

Em contexto hospitalar, a enfermagem se faz presente em cada etapa do ciclo vital, do nascimento à morte. Os profissionais de enfermagem estão envolvidos direta e constantemente nos cuidados a doentes em processo de morte e após a constatação médica do óbito; e são ainda responsáveis pelo preparo, identificação e encaminhamento do corpo. Tais cuidados exigem elevado senso de responsabilidade na tomada de decisões complexas e rápidas, além da reorganização contínua de prioridades e ampla variedade de informações 3 .

Em falas e atitudes, profissionais de enfermagem demonstram compreender que os cuidados frente à finitude vão além das necessidades psicobiológicas e abrangem dimensões sociais, culturais e espirituais ${ }^{4}$. Devido à proximidade diuturna, são estabelecidos vínculos afetivos e não raro, quando ocorre a morte de um doente a quem se dedicam muitas horas de trabalho, estes profissionais podem vivenciar sentimentos semelhantes aos da perda de familiares, denotando um sentido de fracasso tanto técnico como pessoal.

A morte vivenciada no cotidiano de hospitais pode produzir, entre profissionais de enfermagem, desgaste emocional em diferentes níveis, o que inclui o sofrimento espiritual que por sua vez pode revelar ou aumentar a intensidade de sintomas físicos ${ }^{5}$. É possível observar uma relação direta entre saúde e bem-estar espiritual, com impactos tanto na assistência prestada quanto na plenitude para com o trabalho exercido.

Testemunhar os processos de saúde-doença em ambientes hospitalares e atuar continuamente nestes cenários pode impactar cada dimensão vital dos profissionais envolvidos, sendo que o recrudescimento do impacto negativo pode acarretar o rompimento da maneira lógica de organizar o pensamento e cognição. A espiritualidade pode auxiliar a lidar com tais processos, sendo um precursor de conforto, estímulo e equilíbrio em contextos de angústia e estresse 6 .

As crenças existenciais, espirituais ou religiosas, podem contribuir para uma interpretação positiva de eventos críticos, bem como um enfrentamento mais eficaz, constituindo uma fonte de energia e amparo que pode fortalecer o indivíduo em busca de uma vida plena de sentidos. 0 coping religioso-espiritual abrange ferramentas de enfrentamento frente a tais eventos, com estratégias que podem ser de busca por significado profundo, conforto espiritual, intimidade com o transcendente e o imanente, e a ressignificação do percurso de vida?.

Definir espiritualidade é algo complexo por envolver diversos significados, propósitos e valores humanos. Como dimensão integrante do ser, engloba não apenas a religiosidade, como também a esperança e a busca de sentido profundo às experiências, e ainda os valores, atitudes, práticas e sentimentos que nascem a partir da relação consigo próprio, com o meio e com o sagrado. A confluência entre fatores sociais, culturais, biológicos, psicológicos e religiosos refere-se a valores pelos quais a pessoa vive e acredita, o estilo de vida que segue, como 
emprega seu tempo, os hábitos que estabelece, tudo isso se reflete como espírito do viver ou espiritualidade 8 .

Embora existam amplas evidências demonstrando a relevância da espiritualidade na saúde, tradicionalmente os currículos de formação nesta área não incluem o tema com profundidade e abrangência necessárias. Deste modo, os profissionais demonstram desconforto não somente para abordar tais questões em sua prática junto a doentes, mas para identificar em si próprios tais estratégias de amparo e segurança frente a conflitos ${ }^{9}$.

Atualmente, tem-se demonstrado que a espiritualidade configura um papel protetivo em questões relacionadas à saúde física e mental, com impactos na qualidade de vida. Observa-se a prevalência de investigações voltadas a pessoas doentes e familiares diante dessa dimensão, assim como, a percepção de profissionais de saúde quanto aos cuidados a serem observados em tais aspectos, promovendo a assistência integral ${ }^{10}$.

Entretanto, nota-se a lacuna de estudos sobre os fatores protetores à saúde psíquica de profissionais de saúde, com destaque à equipe de enfermagem, considerando as características inerentes ao cuidado frente a processos de finitude e, ainda, de que maneira a espiritualidade poderia permear, modificar ou ressignificar tal vivência.

0 presente estudo tem como objetivo descrever as dimensões do cuidar frente à morte e a influência da espiritualidade na percepção de profissionais de enfermagem atuantes em setores de pronto-atendimento e internação de um hospital universitário.

\section{MÉTODO}

Trata-se de estudo descritivo com delineamento qualitativo, através do qual se busca a investigação de relações, costumes e opiniões, dados subjetivos e não quantificáveis que representam o produto das interpretações que os humanos fazem a respeito de como vivem, expressam o que sentem, pensam, constroem seus artefatos e a si mesmos ${ }^{11}$.

Utilizou-se como suporte teórico-metodológico a Teoria das Representações Sociais (TRS), que busca abstrair sentido, introduzir ordem e percepções que permitam reproduzir o mundo de forma significativa. A informação recebida é filtrada através de cognições e valores próximos à percepção da realidade do indivíduo, a partir de modelos e crenças presentes e compartilhados no contexto do grupo ao qual pertence ${ }^{12}$.

0 estudo foi realizado em um hospital geral situado na região sudeste de Minas Gerais. Foram selecionados os setores de pronto-atendimento e internação: Pronto-Socorro Adulto, Pronto Socorro Infantil, Pediatria, Neurologia, Terapia Intensiva Adulto, Terapia Intensiva Coronariana, Terapia Intensiva Neonatal e Pediátrica, Doenças Infecto-Parasitárias, OncoHematologia, Clínica Médica, Clínica Cirúrgica, Ortopedia, Berçário, Ginecologia e Alojamento Conjunto. Optou-se por excluir do estudo os setores caracterizados por atendimento ambulatorial, no intuito de manter homogeneidade das características assistenciais.

A amostra foi aleatória e intencional, composta de enfermeiros, auxiliares e técnicos de enfermagem de ambos os sexos, com idade igual ou superior a 18 anos. Como critérios de inclusão, selecionou-se aqueles que prestam assistência a pessoas em estágios diversos de saúde ou adoecimento, inclusive em processo de morte. Foram excluídos os profissionais que estavam de licença ou férias durante o período previsto para a coleta, além daqueles que não atuam em cuidados diretos aos doentes.

Houve treinamento e supervisão da equipe de entrevistadores, composta por doze graduandos em saúde. Foram explicitados os objetivos e o roteiro do estudo, com a orientação de não modificar as perguntas nem opinar nas respostas; entretanto seria plausível refazer a pergunta ou acrescentar colocações como: "Tem algo mais a dizer?", "Poderia me explicar novamente?". 
A uniformização dos procedimentos de coleta foi verificada através de testes-piloto com profissionais dos setores envolvidos, o que permitiu averiguar a adequação do instrumento. Tais resultados preliminares foram excluídos após a transcrição, não sendo considerados na análise.

0 instrumento de coleta foi elaborado pelas pesquisadoras responsáveis e contemplou dados para caracterização da amostra, referentes a gênero, idade, nível de atuação, tempo de exercício profissional e setor/serviço. 0 roteiro de entrevista abordou sequencialmente as questões: Como é, para você, cuidar de pacientes em processo de morte? O que é espiritualidade para você? Você acredita que a espiritualidade auxilia a lidar com este aspecto da sua profissão? De que forma? Cada formulário de coleta foi previamente identificado por código alfanumérico, utilizado para cadastro de resultados.

A coleta de dados ocorreu pelo período de dois meses - agosto e setembro de 2016. Para garantir maior participação, as entrevistas individuais eram acertadas com os profissionais nos próprios setores em horários e períodos de conveniência para os pesquisandos, e foram realizadas em locais previamente selecionados nos setores designados, para manter privacidade e livre expressão das ideias.

A duração de cada entrevista variou entre dez e 30 minutos, conforme a disponibilidade do voluntário. As entrevistas foram gravadas em formato de áudio por dispositivos eletrônicos e transcritas pelos entrevistadores na íntegra, exceto por dados de caracterização da amostra e informações que identificassem a autoria das falas. Buscou-se assim preservar o teor original das respostas obtidas, como o sentido atribuído a expressões e silêncios.

Os dados de caracterização foram tabulados e submetidos à análise exploratória por meio de frequências simples. Para sistematizar o tratamento de dados qualitativos resultantes da transcrição das entrevistas, optou-se por utilizar o software DSCSoft ${ }^{\circledR}$, elaborado com base no método do Discurso do Sujeito Coletivo (DSC). Este método consiste em uma técnica de tabulação e organização de dados qualitativos, o qual resulta de expressões-chaves identificadas em trechos mais expressivos das entrevistas e que representam a profundidade das respostas individuais e as ideias centrais que sintetizam o discurso revelado ${ }^{12}$. 0 discursosíntese é escrito na primeira pessoa do singular, nos quais o pensamento de um coletivo é expresso como um discurso individual ${ }^{12}$.

O projeto foi apreciado pelo Comitê de Ética em Pesquisa da Instituição em estudo, aprovado sob o parecer número 1.715.828, CAAE 55434616.0.0000.5154. Após aprovação, feito contato com as chefias dos setores envolvidos, para esclarecimentos a respeito da pesquisa, os objetivos e procedimentos metodológicos.

Os profissionais que aceitaram participar assinaram o Termo de Consentimento Livre e Esclarecido - TCLE onde constam os objetivos, a garantia de sigilo sobre quaisquer dados que possam identificá-los e o direito de retirar-se do estudo a qualquer momento. Cada instrumento recebeu previamente um código numérico aleatório para garantir o anonimato e confidencialidade das informações.

\section{RESULTADOS}

Participaram do estudo 160 indivíduos, dos quais 141 eram do sexo feminino, com idades entre 20 e 60 anos. Quanto à categoria de atuação, foram 131 profissionais de nível médio (auxiliares/técnicos de enfermagem) e 29 de nível superior (enfermeiros/as).

Relativo ao tempo de assistência, a amostra envolveu graus variados de vivência hospitalar, desde indivíduos recém- iniciados na carreira até aqueles com mais de 30 anos de atuação em setores de internação (Tabela 1). 
Tabela 1. Variáveis sóciodemograficas dos profissionais de Enfermagem de um Hospital Universitário. Uberaba, Minas Gerais, 2016.

\begin{tabular}{lrr}
\hline Variáveis & F & \% \\
\hline Sexo & 19 & 11,8 \\
Masculino & 141 & 88,2 \\
Feminino & & \\
Faixa etária & 22 & 13,8 \\
$20-29$ anos & 71 & 44,3 \\
30-39 anos & 35 & 21,8 \\
$40-49$ anos & 25 & 15,7 \\
$50-59$ anos & 7 & 4,4 \\
60 anos e acima & & \\
Tempo de exercício profissional (anos completos) & 14 & 8,7 \\
Menos de 5 anos & 55 & 34,4 \\
5 a 9 anos & 40 & 25,0 \\
10 a 14 anos & 19 & 12,0 \\
15 a 19 anos & 12 & 7,5 \\
20 a 24 anos & 6 & 3,3 \\
25 a 29 anos & 14 & 8,7 \\
30 anos e acima & & \\
Religião ou crença referida & 57 & 35,6 \\
Católico & 52 & 32,5 \\
Espírita & 27 & 16,9 \\
Evangélico & 7 & 4,4 \\
Cristão/ Crê em Deus & 4 & 2,5 \\
Outras denominações & 13 & 8,1 \\
Não informa & $\mathbf{1 6 0}$ & $\mathbf{1 0 0 , 0}$ \\
\hline Total & \multicolumn{2}{c}{} \\
\hline
\end{tabular}

0 agrupamento das expressões-chave e ideias centrais semelhantes resultou em três categorias, sendo: Atuação profissional frente a processos de morte; Olhar para si; e Espiritualidade: dimensões e influência no contexto profissional.

Após selecionar e organizar as expressões-chave presentes em cada relato, foram identificadas as ideias centrais com sentidos semelhantes. Posteriormente, foram editados os DSC correspondentes pela complementaridade dos depoimentos. Estes DSC subsidiaram a formulação de três categorias temáticas descritas na figura 1 a seguir:

Figura 1. Categorias Temáticas. Uberaba, Minas Gerais, 2016.

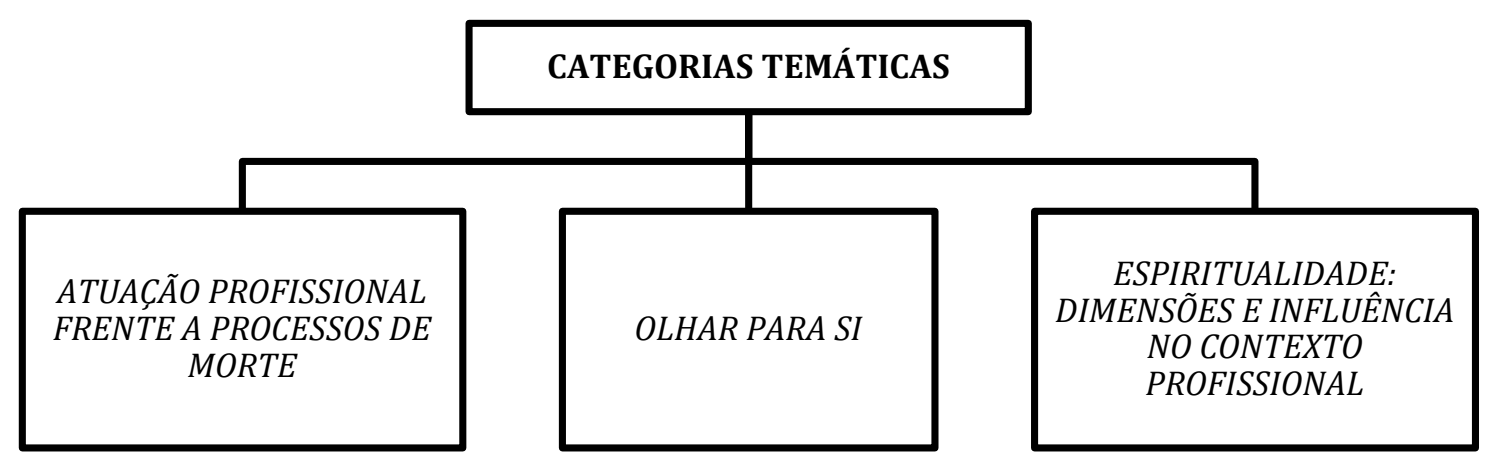


A categoria temática "Atuação profissional frente a processos de morte" abrange as percepções dos profissionais no tocante ao cuidado prestado a pessoas em processo de morte. É possível depreender que os profissionais são permeáveis aos sentimentos e vivências do doente e seus familiares neste contexto, conforme o DSC a seguir:

Lidar todo dia com a doença e a morte nem sempre vai ter resultados positivos; não se torna de fato natural, mas faz parte. Não quer dizer que a gente é frio mas acostuma, porque alguém tem que cuidar. A gente tem uma visão muito errônea de que todo paciente melhore, às vezes o que é melhor pra gente não é o melhor pra ele. Tem aqueles que aceitam a morte de um jeito muito natural, são tranquilos e família também; essa passagem se torna algo mais sereno. Além da dor, o doente sabe que pode acontecer a morte, fica mais deprimido, sensível. Você vê que a pessoa está com medo. A atenção é maior sobre o sentimento dele, o que está passando, os desejos, o que ele ainda quer nesse processo. Ver a família ali sofrendo e não poder falar que está chegando a hora, mentir o tempo todo, dizer que vai melhorar mesmo sabendo que isso não vai acontecer. Você olha o perfil da pessoa e vê se ela está aberta para isso, fala uma mensagem, conforta. Tem que dar incentivo, esperança, fé que vai ficar tudo bem (E43; E139; E23; E09; E44; E82; E01; E16; E96).

Por seu turno, a categoria temática "Olhar para si" reúne relatos de situações potencialmente geradoras de perturbações emocionais e psicológicas, relacionadas às ações de cuidado prestado a pessoas gravemente enfermas. As falas denotam algumas estratégias elencadas para lidarem com tais demandas, como destacam alguns fragmentos a seguir:

Me sinto bem impotente sabendo qual vai ser o fim, tem esse sentimento de incapacidade. Chega a ser frustrante, não pode fazer nada pra mudar aquela situação, não está nas suas mãos. Tento fazer meu melhor enquanto estou ali, não deixo afetar meu comportamento no trabalho nem levar para o lado pessoal, trabalhar o outro lado, senão a gente não tem vida lá fora. Temos que trabalhar muito nosso emocional para prestar um melhor cuidado, humanizado, da melhor forma possível. Ao longo do tempo fui desenvolvendo uma força, tanto para ajudar a família e o paciente, quanto para não ficar levando aquilo para casa. Procuro não me envolver muito pra não sofrer depois, mas essas coisas fogem do alcance, acabam mexendo com o psicológico e tem que fazer esse equilíbrio, não ser totalmente gelada mas não se apegar muito, estar com emocional bem estabilizado para dar conta. Eu sofro, mas acho que a gente vai ficando um pouco mecânico e mais frio, o dia a dia faz isso (E38; E145; E54; E92; E16; E25; E67).

E na categoria temática "Espiritualidade: dimensões e influência no contexto profissional", os relatos denotam aspectos na vivência da espiritualidade no cotidiano, em seu aspecto imanente, com destaque à forma de se relacionar com o meio e os demais. Também falam da dimensão espiritual como a transcendência da matéria, denotando atribuição de um sentido de sacralidade à assistência em fase final da vida:

É o cuidado que a gente tem com a alma, porque não é só do corpo que tem que cuidar. Está na maneira de sentir e de agir com as pessoas, se mostrar como é, saber encarar e entender a situação com paciência. É uma forma humanizada de cuidar das coisas do seu dia a dia, da sua experiência aqui, na sua passagem como ser humano, sempre buscando sintonia entre a vida material e a vida espiritual. A gente só consegue ficar na enfermagem se crer em algo superior, que nos dá apoio, respaldo até pra nossa sanidade, senão desiste. A gente acaba achando um conforto no que acredita. A fé é um fundamento muito importante, quem acredita é capaz de superar os momentos de conflito e fases mais difíceis da vida, mantém o equilíbrio. Ter uma base espiritual ajuda no dia a dia, a gente se pega em uma energia maior, nela se sustenta e passa a ver com outros olhos. Nos auxilia a ter mais forças para cuidar, mais serenidade. Acaba se preparando para estar um pouquinho melhor, apaziguar a alma e o coração de cada um. Esse olhar faz com que seja cada dia melhor dentro da profissão, pode-se ver o quadro com uma compreensão maior, ter mais calma, intuição e sabedoria no cuidado (E22; E116; E38; E42; E107; E04; E32; E23; E21; E80; E122).

\section{DISCUSSÃO}

A equipe de enfermagem atua em todas as fases de adoecimento até o preparo do corpo, após a constatação do desfecho fatal. Entretanto, lidar com este aspecto da profissão pode causar desgaste físico e psíquico, bem como despertar questionamentos e reflexões. Devido às características que denotam o cuidado frente a processos de morte, tais situações podem ocasionar sofrimento a quem cuida.

Frente ao processo de morte, o profissional de enfermagem pode ser o último a permanecer junto a quem está partindo. Quando outros membros da equipe de saúde se afastam do doente, considerando-se impotentes para recuperar a plenitude de um corpo físico, 
a enfermagem persiste, acompanhando o continuum viver/morrer, enquanto há um sopro de vida e mesmo quando este se vai, para preparar o corpo com dignidade 13 .

Profissionais de enfermagem são os principais responsáveis pelo cuidado ao doente em final de vida em contexto hospitalar. Quer seja em contexto emergencial ou após internações, a proximidade ao moribundo os convida a refletir. Embora a morte faça parte do cotidiano de trabalho dos profissionais de enfermagem, persistem as dificuldades em falar sobre o assunto, pois remete à inevitabilidade da finitude humana ${ }^{14}$.

Alguns profissionais reagem com negação à chegada do momento de desfecho fatal, o que pode interferir na forma como cuidam. Outros buscam na naturalização do assunto uma forma de elaborar seus sentimentos, vivenciando este processo de forma mais humanizada. Desta forma, o que pode parecer uma atividade frenética em torno do leito talvez represente, por parte dos profissionais de enfermagem, ansiedade e negação da iminência da morte ${ }^{15}$. Isso pode resultar em comportamentos como a relutância em interagir com a família e o doente, $o$ adiamento de conversas difíceis e uma estrita dedicação a tarefas de conforto físico.

A morte que ocorre no tempo natural, de forma digna e respeitosa é conhecida como ortotanásia. Entretanto, há possibilidade de os profissionais praticarem o contrário, por sentirem que devem investir (ou insistir) em salvar a pessoa a quem se conferiu cuidados ${ }^{15}$. Para tanto, discutem-se maneiras efetivas de preparar o profissional para lidar com a finitude em sua prática.

0 trabalho da enfermagem é permeado por um olhar amplo, voltado a assegurar humanização e integralidade do cuidado. Porém, quando a assistência precisa concentrar-se no processo de morte e morrer, emergem sentimentos perturbadores, conflitos íntimos e mesmo vazio existencial. Profissionais reportam tristeza, fracasso, angústia, impotência, insegurança, culpa, dor e medo como sentimentos que podem emergir a partir do cuidado ao ser que está partindo. Assim, podem manter uma atitude neutra e tecnicista como forma de evitar o sofrimento ${ }^{16}$.

É importante entender que o cuidado integral proporciona qualidade à vida que resta $\mathrm{e}$ possibilita uma morte digna, o que permite ressignificar o sentido da atuação que visa cuidar, além de tratar. Gerenciar tais componentes torna o profissional apto a lidar melhor com as demandas de pacientes, familiares, e dos próprios sentimentos ${ }^{16}$.

Os profissionais de enfermagem registram como marcantes as lembranças relativas ao cuidado de pessoas com quem estabeleceram vínculo afetivo e temem falhar em amenizar o sofrimento alheio. A juventude do indivíduo sob cuidados, bem como o histórico clínico, cronicidade de dor e sofrimento, são os fatores que mais remetem a sofrimento para quem cuida ${ }^{17}$.

Testemunhar sentimentos expressos pelo doente e a reelaboração da existência frente à morte são fatores percebidos como causa de sofrimento relacionado ao trabalho. 0 recrudescimento de emoções negativas e a falta de oportunidades para expressar livremente suas experiências pode ocasionar sofrimento em diversos níveis de profundidade, inclusive de dimensão existencial, levando a se questionar a própria prática17.

Há uma interdependência entre cuidar de si e do outro. Na perspectiva de Foucault, cuidar(-se) é exercício de biopoder. Neste entendimento, o olhar para si como sujeito digno de cuidado remete a questões éticas e de liberdade, convertendo-se em ferramenta de enfrentamento a discursos totalitários de controle de práticas e saberes, no intuito de padronizar a vida subjetiva em prol do bem coletivo18.

0 cuidado de si engloba os espectros físico, mental e espiritual, sendo uma busca individual, mas que se concretiza no encontro com o outro, evidenciando a necessidade de viver harmonicamente em grupo. Busca-se entender o cuidado de si como algo a ser conquistado através de conhecimento interior, o que potencializa o entendimento do que é essencial em si e no outro ${ }^{19}$. 
É necessário compreender os aspectos individuais e coletivos inerentes ao cotidiano que podem interferir na qualidade de vida dos profissionais que cuidam, para que se sintam também cuidados. A criação de locais de acolhimento e escuta ou ainda, a realização de rodas de conversa são iniciativas que podem contribuir para a vivência genuína do diálogo, aumentando a motivação dos profissionais de enfermagem. Desta maneira, deve-se pensar em espaços de partilha solidária, nos quais cuidado, competência e experiências se encontrem ${ }^{20}$.

A formação em saúde deveria contemplar espaços para explanação, escuta e acolhimento de sentimentos e atitudes frente à morte, utilizando-se de diferentes estratégias didáticas que oportunizem a aproximação gradual ao cenário da assistência. Ainda que o aprendizado teórico não possa reproduzir fielmente os diversos níveis de impacto produzido pelas vivências do cotidiano de profissionais em espaços terapêuticos, a abordagem psicopedagógica pode abrandar o impacto que a experiência de lidar com a morte causaria na vida pessoal e acadêmica desses futuros profissionais ${ }^{7}$.

As políticas de humanização preveem o cuidado a quem cuida. Discussões em equipe sobre a atuação frente a processos de morte e os impactos causados em diferentes níveis individuais, de forma que tais situações não sejam naturalizadas ou banalizadas, pode contribuir para amenizar o sofrimento psíquico diante da impotência frente a finitude da vida 21 . Os voluntários do presente estudo também mencionam o anseio de falar e ouvir suas experiências entre pares, como forma de validar ou refutar percepções e reverberações decorrentes do exercício profissional.

Considerando que trabalhadores contemplados em suas necessidades desenvolvem maior empenho com o trabalho realizado, deveria ser meta precípua de instituições que prestam assistência a doentes gravemente enfermos, com possibilidade cotidiana de ocorrência de óbito, a valorização dos profissionais diretamente envolvidos nestas circunstâncias, o que pode refletir diretamente na qualidade da assistência prestada e maior satisfação com o atendimento 21 .

Cada indivíduo tem sua maneira peculiar de enfrentar situações de sofrimento frente à perspectiva da morte. Alguns indivíduos evitam criar vínculos afetivos, o que constitui um paradoxo pois, ao mesmo tempo em que mobiliza variadas emoções em quem cuida, a assistência à pessoa prestes a morrer demanda uma conduta de proteção e manejo de sentimentos e emoções do outro. Sugere-se a busca de conforto espiritual como estratégia para minimizar os abalos psicoemocionais causados no cotidiano do cuidar/assistir 22

No intuito de analisar estratégias de enfrentamento utilizadas por profissionais de enfermagem, apontam-se diferentes maneiras de lidar com o sofrimento, sendo notória a influência da espiritualidade como recurso mitigador do estresse laboral. A espiritualidade é definida como característica individual e intrínseca ao ser, vai além da religiosidade, envolve questões do propósito da vida e o seu significado, representando uma ligação do " $E u^{\prime}$ " com o Universo e com outras pessoas 23 .

A espiritualidade constitui um constructo importante para profissionais de enfermagem que lidam com processos de morte em seu cotidiano, no que tange ao conforto espiritual ao doente e aos familiares, e a ressignificação de eventos potencialmente estressores para o profissional e estabelecimento de um sentido mais elevado ao seu trabalho. Esta dimensão provê uma via terapêutica tanto ao outro como a si próprio, possibilitando cuidado integral e humanizado 24 .

\section{CONCLUSÃO}

Prestar assistência a pessoas gravemente enfermas, além de prover ambiente seguro e acolhedor para que os familiares vivenciem os momentos de despedida, pode gerar sentimentos conflitantes e sofrimento existencial entre profissionais de enfermagem. 
Os discursos dos profissionais demonstra o reconhecimento, valorização e a busca pelo desenvolver aspectos relacionados à espiritualidade. As estratégias elencadas em relação tanto à transcendência, como em seu relacionamento consigo mesmos, com os demais e com o meio em que vivem, denota a busca por um cuidado integral e significativo.

Os profissionais que cuidam são também dignos de cuidados. E, verifica-se anseio por espaços de escuta e acolhimento na própria instituição em que atuam. A escuta entre os pares oportuniza compartilhar experiências, sentimentos e as reelaborações necessárias frente a situações críticas, para que continuem a encontrar sentido e propósito em cuidar, o que pode refletir em ações humanizadas e trazer mais satisfação com o trabalho.

Como limitação do estudo, aponta-se a coleta dos dados em apenas uma instituição. Ainda que seja um número significativo de entrevistas, estas retratam as ideias circulantes e validadas em um estrato delimitado por políticas institucionais.

Por sua vez, espera-se ter contribuído para ampliar a compreensão acerca das percepções de profissionais de enfermagem sobre o cuidar frente ao processo de morte, além da influência da espiritualidade em suas atitudes e reflexões, na forma de se relacionar consigo próprios e com os demais. Salienta-se a importância de estudos posteriores, de maneira que se possa traçar um perfil histórico no que tange às percepções e reverberações do cuidado de enfermagem em cada processo vital e do cuidar de si mesmo como fator de proteção para o bem-estar do profissional.

\section{REFERÊNCIAS}

1. Santos SC, Almeida DB, Silva GTR, Santana GC, Silva HS, Santana LS. Identidade profissional da enfermeira: uma revisão integrativa. Rev Baiana Enferm. [Internet]. 2019 [citado em 31 jan 2020]; 33:e29003. Disponível

em

https://portalseer.ufba.br/index.php/enfermagem/article/view/29003/20115

2. Gonçalves MJR, Simões JRS. A percepção do enfermeiro no lidar com a morte durante a assistência. Rev JRG [Internet]. 2019 [citado em 19 jan 2020]; 2(5):166-82. Disponível em http://revistajrg.com/index.php/jrg/article/view/77

3. Silva RS, Pereira A, Nóbrega MML, Mussi FC. Construção e validação de diagnósticos de enfermagem para pessoas em cuidados paliativos. Rev Latinoam Enferm. [Internet]. 2017 [citado em 28 jan 2020]; 25:e2914. Disponível em: https://www.scielo.br/pdf/rlae/v25/pt_0104-1169-rlae-25-e2914.pdf

4. Lima SF, Vale HGQP, Silva VSC, Pasklan ANP, Reis LMCB, Noronha FMF. Representações sociais sobre o cuidado paliativo entre profissionais de enfermagem. Rev Enferm UFPE on line [Internet]. 2017 [citado em 28 jan 2020]; 11(Supl 5):1980-8. Disponível em: https://periodicos.ufpe.br/revistas/revistaenfermagem/article/download/23351/18965

5. Tavares MM, Gomes AMT, Barbosa DJ, Rocha JCC, Bernardes MMR, Thiengo PCS. Espiritualidade e religiosidade no cotidiano da enfermagem hospitalar. Rev Enferm UFPE on line [Internet]. 2018 [citado em 25 jan 2020]; 12(4):1097-102. Disponível em: https://periodicos.ufpe.br/revistas/revistaenfermagem/article/download/234780/28688

6. Souza MCS, Sousa JM, Lago DMSK, Borges MS, Ribeiro LM, Guilhem DB. Evaluation of the death attitude profile-revised: a study with health science undergraduate students. Rev Texto Contexto Enferm. [Internet]. 2017 [citado em 15 dez 2019]; 26(4):8 telas. Disponível em: http://www.scielo.br/pdf/tce/v26n4/en_0104-0707-tce-26-04-e3640016.pdf

7. Foch GFL, Silva AMB, Enumo SRF. Coping religioso/espiritual: uma revisão sistemática de literatura (2003-2013). Arq Bras Psicol. [Internet]. 2017 [citado em 15 dez 2019]; 69(2):53-71. Disponível em: http://pepsic.bvsalud.org/pdf/arbp/v69n2/05.pdf

8. Copello LE, Pereira ADA, Ferreira CLL. Espiritualidade e religiosidade: importância para o cuidado de enfermagem de paciente em processo de adoecimento. Discipl Scientia Saúde 
[Internet]. 2018 [citado em 27 jan 2020]; 19(2):183-99. Disponível em: https://periodicos.ufn.edu.br/index.php/disciplinarumS/article/view/2504/2166

9. Silva JB, Aquino TAA, Silva AF. As relações entre espiritualidade e cuidado segundo as concepções de estudantes de enfermagem. Rev Enferm UFPE on line [Internet]. 2016 [citado em 23 jan 2020]; 10(3):1029-37. Disponível em https://periodicos.ufpe.br/revistas/revistaenfermagem/article/viewFile/11055/12471

10. Moreira-Almeida A, Lucchetti G. Panorama das pesquisas em ciência, saúde e espiritualidade. Ciênc Cult. [Internet]. 2016 [citado em 23 jan 2020]; 68(1):54-7. Disponível em: http://cienciaecultura.bvs.br/pdf/cic/v68n1/v68n1a16.pdf

11. Polit DF, Beck CT. Fundamentos de pesquisa em enfermagem. 7ed. Porto Alegre: Artmed; 2011.

12. Lefevre F, Levefre AM. Pesquisa de representação social: um enfoque qualiquantitativo. 2ed. Brasília, DF: Liber Livro Editora; 2012. 224 p.

13. Magalhães ALP, Erdmann AL, Souza FGM, Lanzoni GMM, Silva EL, Mello ALSF. Significados do cuidado de enfermagem ao paciente em morte encefálica potencial doador. Rev Gaúcha Enferm. [Internet]. 2018 [citado em 27 jan 2020]; 39:e2017-0274. Disponível em: http://www.scielo.br/pdf/rgenf/v39/1983-1447-rgenf-39-01-e2017-0274.pdf

14. Baldissera AE, Bellini LC, Ferrer ALM, Barreto MS, Coimbra JAH, Marcon SS. Perspectiva de profissionais de enfermagem sobre a morte na emergência. Rev Enferm UFPE on line [Internet]. 2018 [citado em 15 dez 2019]; 12(5):1317-24. Disponível em: https://periodicos.ufpe.br/revistas/revistaenfermagem/article/download/234545/28878 15. Ferreira JMG, Nascimento JL, Sá FC. Profissionais de saúde: um ponto de vista sobre a morte e a distanásia. Rev Bras Educ Méd. [Internet]. 2018 [citado em 15 dez 2019]; 42(3):87-96. Disponível em: https://www.scielo.br/pdf/rbem/v42n3/1981-5271-rbem-42-3-0087.pdf 16. Bastos RA, Lamb FA, Quintana AM, Beck CLC, Carnevale F. Vivências dos enfermeiros frente ao processo de morrer: uma metassíntese qualitativa. Rev Port Enferm Saúde Mental [Internet]. 2017 [citado em 27 jan 2020]; 17:58-64. Disponível em: http://www.scielo.mec.pt/pdf/rpesm/n17/n17a08.pdf

17. Prado RT, Leite JL, Castro EAB, Silva LJ, Silva IR. Desvelando os cuidados aos pacientes em processo de morte/morrer e às suas famílias. Rev Gaúcha Enferm. [Internet]. 2018 [citado em 17 jan 2020]; 39:e2017-0011. Disponível em: http://www.scielo.br/pdf/rgenf/v39/19831447-rgenf-39-e2017-0111.pdf

18. Gomes MM, Ferreri M, Lemos F. O cuidado de si em Michel Foucault: um dispositivo de problematização do político no contemporâneo. Fractal Rev Psicol. [Internet]. 2018 [citado em 31 jan 2020]; 30(2):189-95. Disponível em http://www.scielo.br/pdf/fractal/v30n2/19840292-fractal-30-02-189.pdf

19. Silva AA, Terra MG, Gonçalves MO, Souto VT. O cuidado de si entre profissionais de enfermagem: revisão das dissertações e teses brasileiras. Rev Bras Ciênc Saúde [Internet]. 2014 [citado em 15 dez 2020]; 18(4):346-52. Disponível em: http://periodicos.ufpb.br/index.php/rbcs/article/viewFile/15263/14081

20. Pawlowytsch PWM, Kovalski E. O entendimento da morte para profissionais de saúde de um hospital geral de Santa Catarina. Rev Saúde Meio Ambiente [Internet]. 2017 [citado em 20 dez 2019]; 6(2):28-38.

http://www.periodicos.unc.br/index.php/sma/article/view/1107

Disponível

em

21. Lima ABS, Oliveira LP, Sá KVCS, Silva EL, Caldas AJM, Rolim ILTP. Sentimentos e percepções da enfermagem frente ao processo de morte e morrer: revisão integrativa. Rev Pesqui Saúde [Internet]. 2016 [citado em 25 jan 2020]; 17(2):116-21. Disponível em: http://www.periodicoseletronicos.ufma.br/index.php/revistahuufma/article/view/6093

22. Luz KR, Vargas OAM, Barlem ELD, Schmitt PH, Ramos FRS, Meirelles BHS. Estratégias de enfrentamento por enfermeiros da oncologia de alta complexidade. Rev Bras Enferm. 
[Internet]. 2016 [citado em 20 dez 2019]; 69(1):59-63. Disponível em: http://www.scielo.br/pdf/reben/v69n1/0034-7167-reben-69-01-0067.pdf

23. Santos NAR, Gomes SV, Rodrigues CMA, Santos J, Passos JP. Coping strategies used by oncology palliative care nurses: an integrative review. Cogitare Enferm. [Internet]. 2016 [citado em 19 jan 2020]; 21(3):1-8. Disponível em https://revistas.ufpr.br/cogitare/article/view/45063/pdf

24. Maciel AMSB, Alexandre ACS, Ferreira DMB, Silva FC. A condição da espiritualidade na assistência de enfermagem oncológica. Rev Enferm UFPE on line [Internet]. 2018 [citado em 19 jan 2020]; 12(11):3024-9. Disponível em: https://periodicos.ufpe.br/revistas/revistaenfermagem/article/download/234609/30497

Editora Associada: Vania Del Arco Paschoal

\section{CONTRIBUIÇÕES}

Raquel Lima Dornfeld contribuiu no desenho, análise e interpretação dos dados e redação. Jurema Ribeiro Luiz Gonçalves participou na análise e interpretação dos dados, redação e revisão.

\section{Como citar este artigo (Vancouver)}

Dornfeld RL, Gonçalves JRL. Desafios do cuidado de enfermagem frente à morte: reflexões sobre espiritualidade. REFACS [Internet]. 2021 [citado em inserir dia, mês e ano de acesso]; 9(Supl. 1):281-291. Disponível em: inserir link de acesso. DOI: inserir link do DOI

\section{Como citar este artigo (ABNT)}

DORNFELD, R. L.; GONÇALVES, J. R. L. Desafios do cuidado de enfermagem frente à morte: reflexões sobre espiritualidade. REFACS, Uberaba, MG, v. 9, p. 281-291, 2021. Supl. 1. DOI: inserir link do DOI. Disponível em: inserir link de acesso. Acesso em: inserir dia, mês e ano de acesso.

\section{Como citar este artigo (APA)}

Dornfeld, R.L., \& Gonçalves, J.R.L. (2021). Desafios do cuidado de enfermagem frente à morte: reflexões sobre espiritualidade. REFACS, 9(Supl. 1), 281-291. Recuperado em inserir dia, mês e ano de acesso de inserir link de acesso. DOI: inserir link do DOI. 